\title{
THE LOCUS OF ACTION OF THE PARATHYROID HORMONE: EX- PERIMENTAL STUDIES WITH PARATHYROID EXTRACT ON NORMAL AND NEPHRECTOMIZED RATS ${ }^{1}$
}

\author{
By THEODORE H. INGALLS, GORDON DONALDSON, AND FULLER ALBRIGHT \\ (From the Harvard Medical School and the Departments of Pediatrics, Surgery, and Medicine \\ of the Massachusetts General Hospital, Boston)
}

(Received for publication January 8, 1943)

\section{INTRODUCTION}

The administration of parathyroid extract causes well-known changes in the calcium and phosphorus metabolisms. Albright and Ellsworth (1) advanced the theory that the changes in the calcium metabolism, including changes in bone, were dependent upon preceding changes in the phosphorus metabolism; they, furthermore, believed that the lowering of the serum phosphorus level was the result of an increased phosphate excretion in the urine. Collip, Pugsley, Selye, and Thomson (2), however, after a study of the long bones of 8 nephrectomized rats that had been injected with parathyroid extract, concluded that the action of the parathyroid hormone on bone tissue is not dependent upon a preceding phosphorus diuresis. Likewise, McJunkin, Tweedy, and McNamara (3) found that the administration of large doses of parathyroid extract to nephrectomized rats produced a pronounced resorption of bone although it did not produce a characteristic rise in serum calcium.

In spite of these studies, there still seemed room for doubt: Collip, et al. did not publish results with nephrectomized controls, and the possibility existed that nephrectomy alone, with its concomitant acidosis, might lead to bone resorption; McJunkin, et al. did publish results on nephrectomized controls, but their control animals were considerably heavier and presumably older than the experimental animals (control animals, 151 grams, as compared with experimental animals, 110 grams, average per animal).

The studies here to be reported are a repetition and an extension of the above observations, with certain modifications and different methods, to determine whether the above results could pos-

\footnotetext{
1 This work was aided by a grant from the Proctor Fund.
}

sibly be due to factors other than the action of the hormone-in particular nephrectomy itself, or the acidity of the substrate containing the hormone. Dr. Granville A. Bennett and two of the authors (G. D. and F. A.) carried out some preliminary experiments on rats, which have never been published, in which they studied histologically the bone lesions in nephrectomized rats, half of which had received parathyroid extract. They were unable to convince themselves that the bone resorption was any greater in the rats which received parathyroid extract than in the nephrectomized controls.

\section{METHODS AND MATERIALS}

Growing rats of 90 to 200 grams in weight, which were bred and raised in the animal farm of the Massachusetts General Hospital, were used in the following 3 experiments. In the first 2 experiments, one tibia of each rat was fixed in 10 per cent formalin, decalcified in dilute nitric acid, sectioned, and stained with hematoxylin and eosin. The other tibia was fixed in 80 per cent alcohol and $x$-rayed. It was then treated with silver nitrate according to a modification of Gomorri's method (4), decalcified and sectioned for histological examination. By these latter procedures, it is possible to demonstrate in situ, calcium deposition or withdrawal; this is impossible to do accurately in sections decalcified by the usual technics. In the third experiment, the results were demonstrated by $\mathrm{x}$-ray alone.

\section{Expcriment 1}

Objective: To study the effectiveness of parathyroid extract in mobilizing calcium salts from the primary spongiosa in the nephrectomized rat.

Procedure: Sixteen growing rats, weighing between 90 and 120 grams, were used. Half were nephrectomized under ether anesthesia. Four nephrectomized and 4 normal animals were given 200 units ( 2 cc.) of parathyroid extract, subcutaneously, twice daily and sacrificed by an overdose of ether, 60 hours after the start of the experiment. The 2 other groups of normal and nephrectomized animals, to which no parathyroid extract was given, served as controls.

Observations: There was definite metaphyseal rarefaction (osteitis fibrosa) at the metaphyses of the long bones 


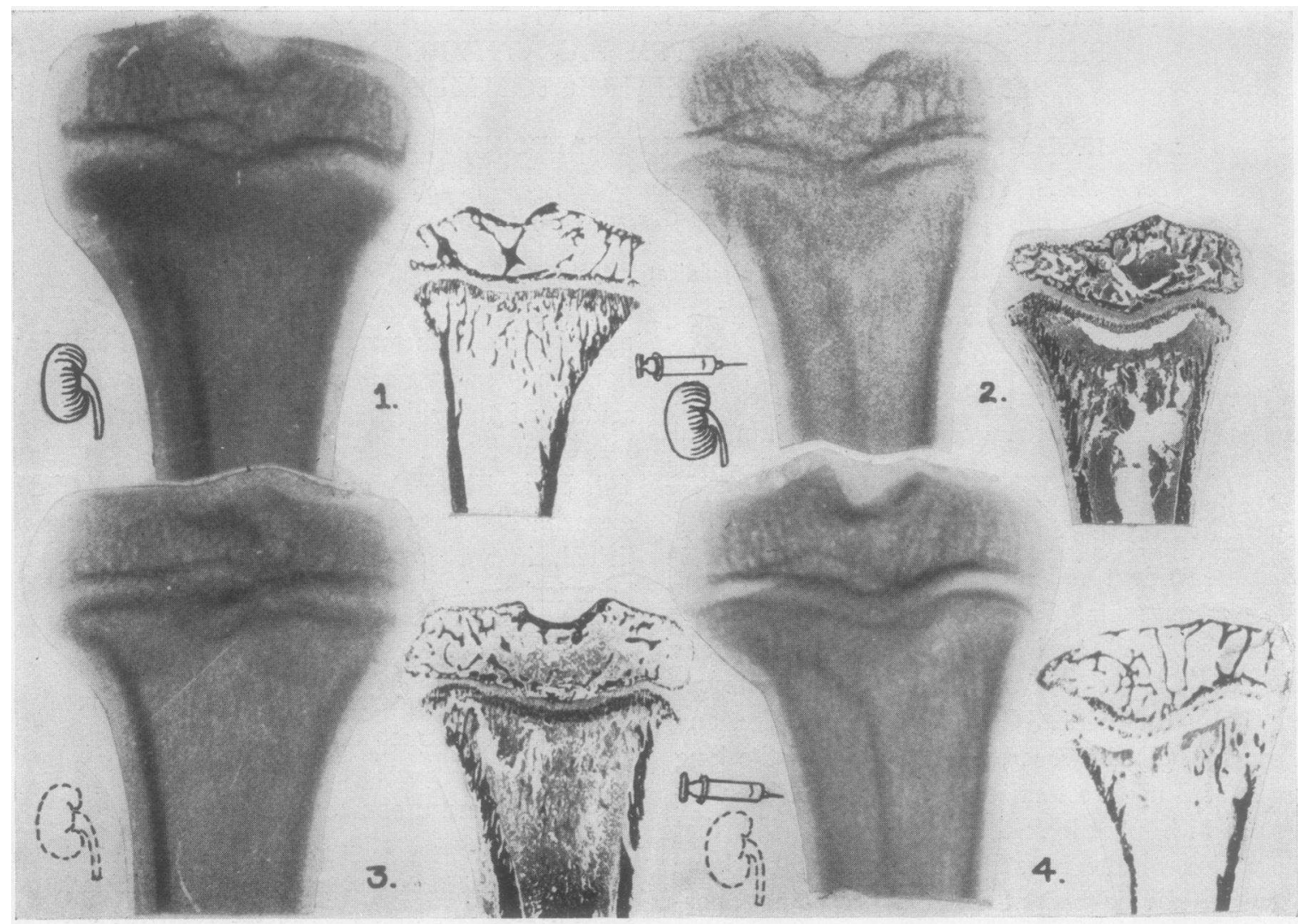

Fig. 1. X-rays and Silvered Sections of the Tibiae of Animals Used in the First Experiment, Sacrificed at 60 Hours

(1) Normal control, (2) normal animal injected with parathyroid extract, (3) nephrectomized animal, (4) nephrectomized animal injected with parathyroid extract.

of animals injected with parathyroid extract, whether the kidneys were intact or extirpated. This was demonstrable both in the roentgenograms and silvered sections (Figure 1). The lesion was indistinguishable in the 2 groups of animals, and was characterized by a relatively complete resorption of the primary spongiosa, which was replaced by a fibrous, soft tissue composed of osteoblasts, foreign body giant cells (osteoclasts), and exudate (Figure 2). One may say, therefore, that in both groups an osteitis fibrosa resulted within 60 hours from the injection of parathyroid extract.

Metaphyseal rarefaction of a different type also occurred in the nephrectomized animals which had not been injected with parathyroid extract. This process, which one might call "renal rickets," 2 differed from that described above, in that decalcification occurred somewhat more distal in the metaphysis, i.c., further from the epiphiseal cartilage. The calcified cartilage (zone of provisional calcification) was less demineralized than was the

2 The quotations are used to differentiate the condition described from the clinical syndrome which has this name. comparable region in the injected animals (Figure 1). There was less disorganization of structure, far less fibrous tissue, and practically no exudate (Figure 2). The disturbance appeared to represent much less extensive decalcification than occurred after the injection of parathyroid extract, the difference being probably qualitative as well but possibly only quantitative.

Comment: In the experiment described, there appeared to be definite indications that parathyroid extract extensively decalcified the metaphysis of the rapidly growing rat tibia, even in the absence of the kidneys. However, the results were complicated by the fact that some decalcification of a lesser degree occurred following nephrectomy alone.

\section{Experiment 2}

Objective: To minimize the complications of renal failure following nephrectomy, by decreasing the duration of the experiment.

Procedure: This experiment paralleled the first except that all the animals (12) were sacrificed 20 hours after the start of the experiment. 


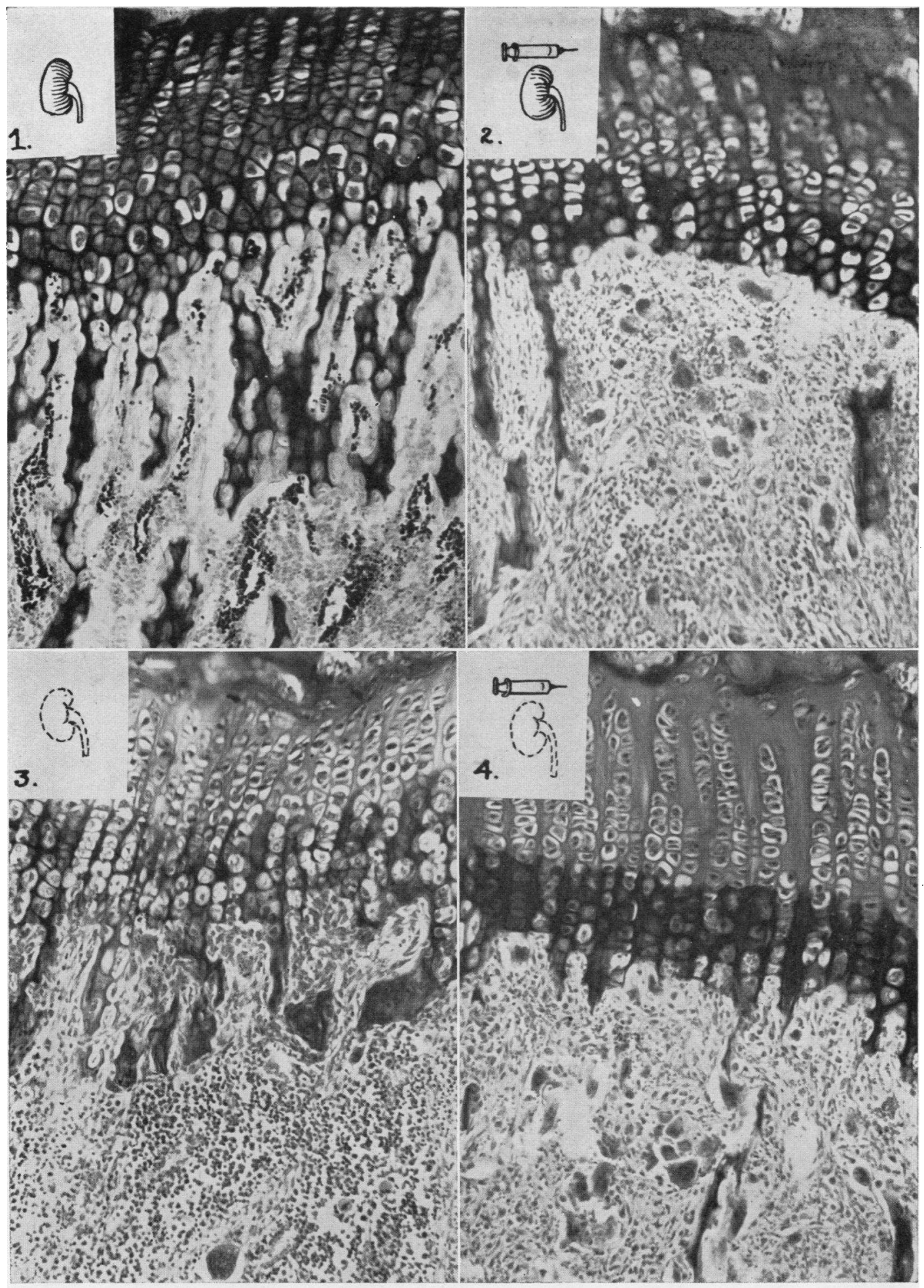

Fig. 2. Microphotographs of Sections of Tibial Metaphyses of Animals Used in the First EXPERIMENT

(1) Normal control, (2) normal animal injected with parathyroid extract, (3) nephrectomized animal, (4) nephrectomized animal injected with parathyroid extract. 
Observations: Both groups (numbering 3 each) of injected animals, whether the kidneys were intact or extirpated, showed the early changes of osteitis fibrosa cystica. There was slight but definite decalcification of the metaphysis as revealed by $\mathrm{x}$-rays and silvered sections, an increase in fibrous tissue, and an abnormally large number of foreign body giant cells in decalcified sections (Figure 3). Neither of the uninjected control groups, whether the kidneys were intact or extirpated, showed any deviation from the normal findings (Figure 4).

Comment: Parathyroid extract was found to be effective in mobilizing calcium salts from the primary spongiosa of the nephrectomized rat, within 20 hours of the start of the experiment described above. Roentgenologic and histologic criteria of decalcification, due to the progressive acidosis known to result from nephrectomy alone, had not developed within that period.

\section{Experiment 3}

Objective: To investigate whether the results observed in the injected, nephrectomized animals could be due to the acidity of the subcutaneously administered parathyroid extract rather than to the hormone.

Procedure: Five rats, each weighing about 180 grams, were used in this experiment. The experiment consisted of 2 parts.

Part A. The parathyroid extract was titrated by our colleague, Esther Bloomberg, to determine the amount of acid present. Each cc. was found to be equivalent to $0.052 \mathrm{cc}$. of $1 / 10 \mathrm{~N} . \mathrm{HCl}$; furthermore, the ash of $1 \mathrm{cc}$. of extract contained only $0.014 \mathrm{cc}$. of $0.1 \mathrm{~N}$. acid. Accordingly, 2 nephrectomized rats were injected with $0.2 \mathrm{cc}$. $1 / 10 \mathrm{~N}$. $\mathrm{HCl}$, twice daily for 2 days; this, of course, was almost double the amount of acid in $2 \mathrm{cc}$. of parathyroid extract and, what is more important, about 7 times the amount of acid in the ash of 2 cc. of parathyroid extract.

Part B. The same question was attacked in an entirely different way. The Eli Lilly Company kindly prepared an inactivated parathyroid extract. This was made by exposing regular parathyroid extract to the action of a small amount of formaldehyde. The free formaldehyde was then removed and the extract was returned to its original concentration and $\mathrm{pH}$. The hormonal activity was roughly 2 per cent of the original extract. The toxicity on mice was reported to be $\mathrm{LD}_{50}$ $=20.58 \mathrm{cc}$. per kgm., intravenously. Two cc. were injected into each of 3 nephrectomized rats, twice daily for 2 days.

Observations: Parts A and B: The animals injected with acid lived between 36 and 48 hours, and died at night, presumably in acidosis. The other 3 , which received the inactivated extract, were sacrificed by an overdose of ether at the end of 48 hours. The tibiae of all 5 rats showed only the type of metaphyseal rarefaction ("renal rickets") which results from nephrectomy alone, as described in the first experiment.

Comment: It seems clear from this third experiment that the bone changes produced in nephrectomized rats from parathyroid extract cannot be due to the acidity of the extract.

\section{DISCUSSION}

From Experiment 1 and Experiment 2, it is quite clear that parathyroid extract has a decalcifying effect on bones, even in the absence of the kidneys. From Experiment 3, it is quite clear that this effect is not due to the acidity of the extract.

From Experiment 1, however, the observation is made that nephrectomy alone leads to bone resorption, albeit not so great and qualitatively somewhat different from that which occurs following administration of parathyroid extract.

The acidosis following nephrectomy is presumably a steadily progressive disturbance; the chemical changes which follow the hypodermic injection of parathyroid extract are prompt in onset, of relatively great intensity, and eventually corrected. One has no way of controlling or equalizing these phenomena so that they can be compared. It would be of interest to determine whether the institution of sudden and marked acidosis would result in the widespread metaphyseal decalcification and disorganization that follows the injection of parathyroid extract in large doses and, per contra, whether the injection of small amounts of parathyroid extract would result in a picture approximating that of "renal rickets."

Whereas the authors feel that the data in Experiment 1 are sufficient to prove that parathyroid hormone has an effect on bone in the absence of kidneys, they would like to be able to report on the results of the following experiment which was started, but not carried through because of the outbreak of war. The first part of the experiment has been partially completed: the concomitant administration of alkalies did not inhibit the effect of parathyroid extract on bone. In the second part of the experiment, it was planned to see whether administration of alkalies would prevent the bone changes following nephrectomy alone. Finally, if such were the case, the third part of the experiment would consist of seeing whether parathyroid extract in nephrectomized rats, receiving enough alkali to prevent the bone changes due to nephrectomy per se, would produce typical bone lesions. If such were the case, one would 


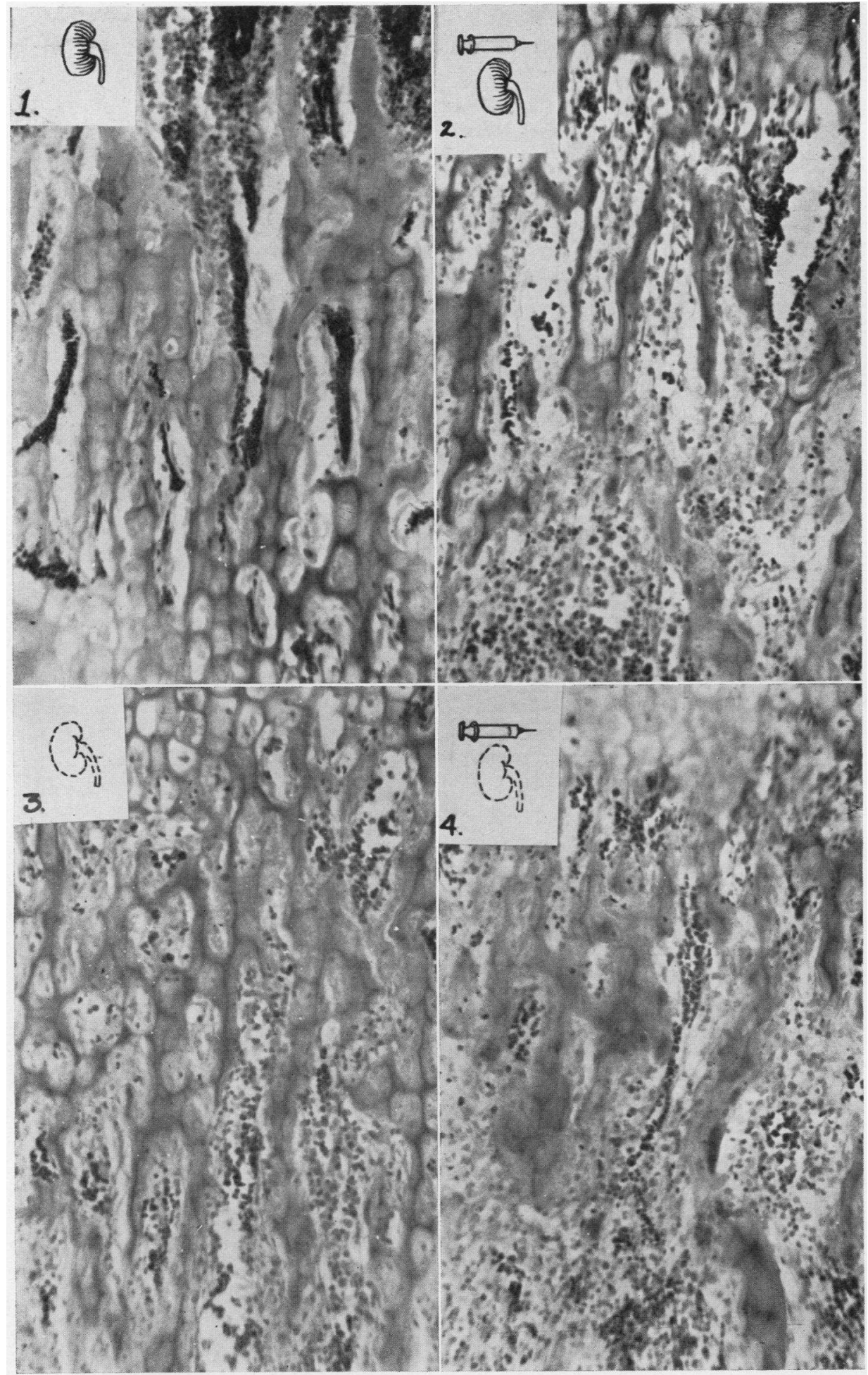

Fig. 3. Microphotographs of Sections of Metaphyses of Animals Used in Second Experiment Sacrificed at 20 Hours

(1) Normal control, (2) normal animal injected with parathyroid extract, (3) nephrectomized animal, (4) nephrectomized animal injected with parathyroid extract. 
have completely ruled out any possibility that the nephrectomy and not the hormone was causing the bone changes.

It will be seen that the evidence here cited supports the point of view that the parathyroid hormone has a direct action on bone tissues and is against the theory strongly held by one of us (F. A.). Further experiments will have to be awaited before it is clear just how far that theory will have to be modified. It seems not improbable that the hormone acts on phosphate metabolism in some way which not only increases excretion of phosphates in the urine, but also apparently produces certain bone changes directly.

\section{SUM MARY}

1. Parathyroid extract produced osteitis fibrosa in rats in 60 hours; the bone lesions were the same, whether or not the rats were first nephrectomized.

2. Nephrectomy alone produced bone resorption in rats in 60 hours; the bone lesions, however, were qualitatively and quantitatively distinguishable from the lesions produced by parathyroid extract.
3. The lesions produced in nephrectomized rats by parathyroid extract were already present in 20 hours, whereas lesions produced by nephrectomy had not yet appeared at that time.

4. Evidence is presented that the effect of parathyroid extract on bone tissue in nephrectomized rats is not attributable to the acidity of the extract.

The authors wish to thank the Eli Lilly Company for supplying the "inactivated parathyroid extract."

\section{BIBLIOGRAPHY}

1. Albright, F., and Ellsworth, R., Studies on the physiology of the parathyroid glands. I. Calcium and phosphorus studies on a case of idiopathic hypoparathyroidism. J. Clin. Invest., 1929, 7, 183.

2. Collip, J. B., Pugsley, L. I., Selye, H., and Thomson, D. L., Observations concerning the mechanism of parathyroid hormone action. Brit. J. Exper. Path., $1934,15,335$

3. McJunkin, F. A., Tweedy, W. R., and McNamara, E. W., Effect of parathyroid extract and calciferol on the tissues of the nephrectomized rat. Am. J. Path., 1937, 13, 325.

4. Ingalls, T. H., Epiphyseal growth: Normal sequence of events at the epiphyseal plate. Endocrinol., 1941, 29, 710 . 